\title{
A ORDEM MORAL MODERNA E A POLÍTICA DO SECULARISMO
}

\author{
MODERN MORAL ORDER AND THE POLITICS OF SECULARISM
}

\author{
LUIZ BERNARDO LEITE ARAUJO* \\ (UERJ / Brasil)
}

\begin{abstract}
RESUMO
$\mathrm{O}$ artigo trata da política do secularismo como um componente essencial da ordem moral moderna, contrapondo a caracterização da secularidade em Charles Taylor às abordagens do tema na ideia de razão pública em John Rawls e na concepção pós-secular de democracia em Jürgen Habermas.
\end{abstract}

Palavras-chave: Secularismo. Modernidade. Democracia. Taylor. Rawls. Habermas.

\begin{abstract}
The article deals with the politics of secularism as an essential component of modern moral order, opposing Charles Taylor's characterization of secularity to the approaches of the issue in John Rawls's idea of public reason and in Jürgen Habermas's post-secular conception of democracy.
\end{abstract}

Keywords: Secularism. Modernity. Democracy. Taylor. Rawls. Habermas.

"Estamos condenados a viver em um consenso sobreposto". Essa afirmação não é de John Rawls, como seria de esperar, mas de Charles Taylor, um de seus mais incisivos e recorrentes críticos $^{1}$. Tanto quanto o primeiro, o filósofo canadense procura identificar formas aceitáveis de convivência e de integração entre os cidadãos de democracias liberais marcadas pela pluralidade de visões de mundo e de concepções do bem. Sendo a "ordem moral moderna" fundada nos princípios básicos dos direitos e liberdades de seus membros (direitos humanos), da igualdade entre eles (não discriminação) e de regras baseadas no consentimento (democracia) ${ }^{2}$, ela não pode ser organizada senão em torno de uma "filosofia da civilidade" surgida dos escombros das concepções cósmicoreligiosas do mundo, dando lugar a uma nova concepção do político em que a ideia de "laicidade" ou "secularidade" tornou-se um componente essencial ${ }^{3}$. A coesão social nas democracias modernas, caracterizadas pela diversidade de perspectivas religiosas, filosóficas e morais que se chocam e se fragilizam mutuamente, depende de uma ética da cidadania firmada por comunidades cujas razões divergem umas das outras, requerendo uma justiça política equidistante das diferentes posições e

\footnotetext{
* Professor do Departamento de Filosofia da Universidade do Estado do Rio de Janeiro (UERJ) e Pesquisador do Conselho Nacional de Desenvolvimento Científico e Tecnológico (CNPq).
} 
uma linguagem pública isenta de premissas extraídas de uma ou outra forma de crença e também - o que é importante - de descrença.

Estabeleceu-se assim, para Taylor, um amplo consenso em torno do caráter laico ou secular de qualquer democracia liberal. Mas um regime secular, cujas principais finalidades são o respeito à igualdade moral dos indivíduos, por um lado, e a proteção à liberdade de consciência e de religião, por outro, deve ser compreendido no âmbito maior da diversidade de crenças e valores - religiosos ou não religiosos - dos cidadãos. Em sua opinião, o chamado "secularismo" diz respeito à resposta do Estado democrático de direito ao problema da diversidade, e não propriamente à relação entre a religião e as instituições políticas. A secularidade a que Taylor se refere contrasta "não só com um fundamento divino para a sociedade, mas também com toda ideia de sociedade como constituída em algo que transcenda a ação comum contemporânea"4 , razão aliás de seu acordo com a formulação rawlsiana do consenso sobreposto entre as diversas doutrinas abrangentes numa "filosofia comum de civilidade", da qual decorre a neutralidade estatal cujo ponto

\footnotetext{
é precisamente evitar favorecer ou desfavorecer não só as posições religiosas, mas qualquer posição básica, religiosa ou não religiosa. Não podemos favorecer o Cristianismo sobre o Islã, mas também não podemos favorecer a religião em detrimento da descrença na religião, ou vice-versa ${ }^{5}$.
}

A complexidade do termo "secular", com todos os seus avatares históricos, desaparece nos modelos teóricos predominantes da secularização - como na abordagem inicial do próprio John Rawls ${ }^{6}$-, cujas narrativas fazem da religião um "caso especial", uma verdadeira "fixação", definindo o secularismo em termos de arranjos institucionais específicos, cuja "fetichização" oblitera o fato de serem eles derivados da busca pelo equilíbrio entre os ideais - nem sempre facilmente combináveis - da ordem moral moderna, e invocando o "muro da separação" ou a "laicidade" - fundados na antinomia entre o secular e o religioso - como critério último da secularidade da época atual ${ }^{7}$.

Taylor se dedica, então, a estudar as profundas modificações da religião nas sociedades ocidentais para compreender o que significa dizer que vivemos em uma Era Secular ${ }^{8}$. Descrevendo com riqueza de detalhes históricos e eruditas observações filosóficas a progressiva passagem de uma sociedade em que era praticamente impossível não acreditar em Deus para uma na qual, até mesmo para o crente mais fervoroso, a fé se apresenta apenas como uma possibilidade humana entre outras, ele propugna uma mudança de foco das duas caracterizações usuais da secularização - esvaziamento 
da religião no espaço público (secularismo 1) e declínio das crenças e das práticas religiosas (secularismo 2) - para um terceiro significado, intimamente relacionado com o segundo e não sem conexão com o primeiro, que privilegia a questão do sentido da vida humana, tratando das "condições da experiência do espiritual e da sua busca"9. Taylor pretende chamar a atenção para a crença e a descrença, não como maneiras pelas quais as pessoas justificam a existência, mas como modos alternativos de vida moral/espiritual, particularmente na dimensão da "plenitude" (fullness), cuja realização se dá na estrutura imanente de uma modernidade ocidental caracterizada pela erosão da certeza imediata e pelo fim da fé religiosa ingênua, isto é, de uma Era Secular na qual o eclipse de todas as metas transcendentes ao próprio florescimento humano tornou-se concebível, na qual "a fé em Deus não é mais axiomática" ${ }^{\prime 1}$. Trata-se de uma alternativa que a narrativa da secularização como "subtração" - implícita tanto no primeiro quanto no segundo significados de secularidade, ambos baseados numa história de ruptura radical da ciência materialista e do humanismo ateu com a antiga tradição religiosa - não é capaz de entender como alteração do horizonte de sentido, como transformação das condições em que se dão a relação com a transcendência e a aspiração humana de completude ${ }^{11}$.

Desse modo, a convergência antes mencionada entre Charles Taylor e John Rawls em torno da incontornabilidade da política do secularismo no contexto da ordem moral moderna deve ser tomada cum grano salis. O filósofo canadense, mesmo vislumbrando na formulação tardia da obra rawlsiana (com razão) a notável abertura da razão pública ao poliglotismo de vozes nas sociedades democráticas, não deixa de acentuar constantemente a ênfase equivocada do liberalismo político na singularidade da religião, a qual é compartilhada por muitos pensadores políticos contemporâneos entre os quais Jürgen Habermas, outro importante contendor nessa querela - prisioneiros de uma visão do secularismo baseada no difundido "mito" do Esclarecimento, vale dizer, "a compreensão do Esclarecimento como um passo absoluto, não mitigado para frente", muitas vezes representado como uma passagem da revelação divina, ou da religião em geral, para a "simples razão" (a blosse Vernunft de Kant $)^{12}$. A despeito de todas as diferenças entre Rawls e Habermas,

eles parecem reservar uma posição especial para a razão não religiosamente informada (chamemo-la de "simples razão"), como se esta última fosse capaz de resolver certas questões político-morais (a) de um modo que possa satisfazer legitimamente qualquer pensador honesto e claro, e (b) onde as conclusões religiosamente embasadas serão sempre duvidosas, e no fim das contas convincentes somente para as pessoas que já tenham aceitado os dogmas em questão ${ }^{13}$. 
É evidente que Taylor tem em mente a concepção independente ou autônoma da justiça política advogada por ambos, respectivamente fundadas no princípio liberal de legitimidade (Rawls) e no princípio do discurso (Habermas) ${ }^{14}$. E, a seu ver, a distinção (a) + (b) aplicada às questões práticas uma forma importante adotada pelo mito da Aufklärung e ancorada em um tríplice movimento originado no fundacionalismo filosófico, no naturalismo científico e no secularismo político depende de algo totalmente infundado, a saber, a distinção em termos de "credibilidade racional" entre discursos religiosos e não religiosos ${ }^{15}$.

De maneira geral, portanto, há um acordo fundamental na literatura recente sobre o tema do secularismo na modernidade - fortemente influenciada pelas últimas investigações realizadas por Taylor, Rawls e Habermas - quanto a uma necessária diferenciação entre a secularização do Estado e a secularização da sociedade. Seja mediante uma radical redefinição do secularismo no primeiro, seja através da delimitação das questões e dos fóruns da razão pública no segundo, seja ainda em virtude das implicações pós-seculares do princípio de tolerância no terceiro, concorda-se que na democracia contemporânea só merecem o epíteto "secularista" aqueles regimes "concebidos não primariamente como muralhas contra a religião", que numa sociedade política democrática, a não ser em caso de incompatibilidade com seus elementos essenciais, a razão pública "não critica nem ataca nenhuma doutrina abrangente, religiosa ou não", e que, finalmente, "a secularização do poder do Estado e as liberdades positivas e negativas do exercício da religião constituem como que dois lados de uma mesma medalha"16. Entretanto, a julgar pela insistência de Taylor em apontar a autossuficiência da razão como um elemento característico compartilhado por Rawls e Habermas malgrado o imenso valor da formulação tardia de um Estado secular no liberalismo político, e, mais enfaticamente, apesar da excepcional recusa de uma desconfiança política em relação à religião na teoria do discurso -, o ponto de litígio capital consistiria na distinção epistemológica entre razão e religião. Trata-se da questão da base normativa do Estado democrático de direito, frente à qual se instaura uma controvérsia cuja origem parece estar na própria polissemia do termo "secular".

Nesta ótica, não há exagero algum em frisar a centralidade da concepção política rawlsiana, cuja terminologia estabelece os contornos principais do debate atual sobre a política do secularismo, inclusive nas intervenções de Taylor e de Habermas ${ }^{17}$. Ora, na segunda introdução de seu Political Liberalism, o filósofo americano identifica na particular atenção com as doutrinas abrangentes não liberais o problema fundamental da obra, apresentando a questão filosófica nela tratada da seguinte maneira: "como aqueles que professam uma doutrina religiosa que se baseia na autoridade religiosa, ethic@-Florianópolis, v. 10, n.3,p.39-53, Dez. 2011. 
por exemplo, da Igreja ou da Bíblia, podem também subscrever uma concepção política razoável que ofereça sustentação a um regime democrático justo?"18 . Rawls promove, então, uma revisão da ideia de razão pública exposta na sexta conferência da obra, sendo que a principal mudança diz respeito à questão de como as mais diversas doutrinas abrangentes - religiosas e seculares - podem coexistir e cooperar de modo razoável e justo numa democracia constitucional, ou ainda quais são os pressupostos comuns para uma atuação aceitável dessas doutrinas distintas e incompatíveis na esfera pública $^{19}$. É nesse contexto que Rawls se refere pela primeira vez ao proviso, especificando o que ele chama de visão ampla da razão pública e adotando uma posição mais inclusiva das razões abrangentes na discussão política. A seu juízo,

\footnotetext{
doutrinas abrangentes razoáveis, religiosas ou não religiosas, podem ser introduzidas na discussão política pública, contanto que sejam apresentadas, no devido tempo, razões políticas adequadas - e não dadas unicamente por doutrinas abrangentes - para sustentar seja o que for que se diga que as doutrinas abrangentes introduzidas apoiam ${ }^{20}$.
}

Em vez de estipular condições para a introdução de doutrinas abrangentes na razão pública, como ainda era o caso até a edição de 1996 do Political Liberalism, Rawls passa a adotar apenas a cláusula que prescreve a apresentação pública de razões estritamente políticas (no devido tempo) pelas doutrinas abrangentes, razões igualmente acessíveis a todos os cidadãos.

Trata-se claramente de uma interpretação mais permissiva da razão pública. O importante, afirma Rawls numa entrevista concedida em 1998,

\footnotetext{
é que as pessoas ofereçam os tipos de razões que possam ser compreendidas e avaliadas para além de suas doutrinas abrangentes particulares. Assim, a ideia de razão pública não é sobre as respostas certas a todas essas questões, mas sobre os tipos de razões com as quais elas deveriam ser respondidas ${ }^{21}$.
}

Na mesma entrevista, Rawls assinala que

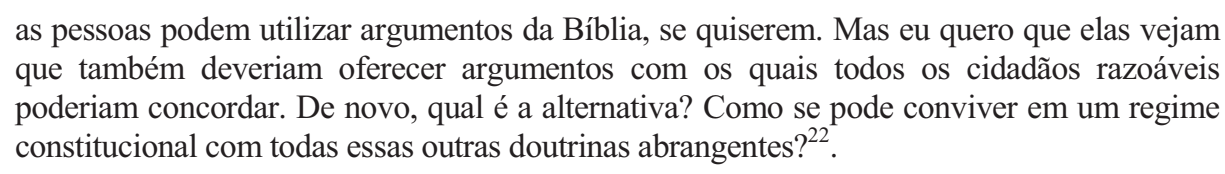


Eu não pretendo detalhar aqui todos os elementos que indicam o crescente interesse do filósofo americano pelo tema da religião na democracia, do qual resulta uma visão cada vez menos restritiva da razão pública no liberalismo político ${ }^{23}$. O fato é que, ao contrário do que Taylor presume, Rawls rejeita a identificação entre "razão pública" e "razão secular", na medida em que esta última se define "como a argumentação que se baseia em doutrinas não religiosas abrangentes", cujos valores "são amplos demais para servir aos propósitos da razão pública" e estão sujeitos às mesmas restrições impostas pelo critério de reciprocidade democrática ${ }^{24}$. Para ele, é preciso diferençar as razões seculares de uma doutrina abrangente não religiosa, por um lado, de uma concepção puramente política que se encontra dentro dos limites do conteúdo da razão pública, por outro, uma vez que "argumentos e conceitos seculares desse tipo [qualquer argumento reflexivo e crítico, publicamente inteligível e racional, $L B L A]$ pertencem à filosofia primeira e à doutrina moral e estão fora do domínio do político" ${ }^{25}$. Por esse motivo, Rawls nega enfaticamente que seus argumentos constituam uma forma velada de secularismo, considerando - não sem alguma ironia - que eles poderiam ser vistos como uma forma velada de religiosidade, o que também não é o caso ${ }^{26}$. A seu juízo, há dois tipos gerais de doutrinas abrangentes, religiosas e seculares, sendo os argumentos políticos em termos de razão pública o solo comum entre elas, o terreno a partir do qual é possível a compreensão e a cooperação mútuas ${ }^{27}$.

A distinção central para Rawls, portanto, não é entre razões seculares e religiosas, mas sim entre razão pública (aplicada a elementos constitucionais essenciais e a questões de justiça básica da “cultura política pública") e razões não públicas (associadas à "cultura de fundo" das instituições e associações da sociedade), diferenciação que - seja dito de passagem - "não corresponde à distinção entre público e privado", porquanto "não existe algo como uma razão privada" 28 . É claro que Rawls se sujeita à objeção de que a razão pública democrática ensejaria uma providencial lingua franca num mundo desprovido de garantias metassociais de ordem religiosa ou metafísica, uma espécie de Esperanto político numa época de diversidade radical. Salvo, porém, submeter-se à contradição performativa típica dos discursos teóricos sobre democracia e pluralismo em termos de antagonismo e hegemonia, a polêmica reside mais no lugar e no âmbito de aplicação da linguagem compartilhada pelos membros da comunidade política do que no caráter religioso ou secular da razão pública. O próprio Taylor admite - à maneira de Rawls, por assim dizer - que "há zonas de um Estado secular em que a linguagem utilizada tem de ser neutra" (...); "as linhas são difíceis de traçar, e devem ser traçadas sempre de novo. Mas tal é a natureza do empreendimento que é o Estado secular moderno. 
E que melhor alternativa existe para democracias diversas?"29 . Neste sentido, a mim me parece que, uma vez removida da ideia rawlsiana de razão pública a possível ambiguidade entre contextos de escolha e de apresentação pública de argumentos que justificariam decisões políticas coercitivas ${ }^{30}$, o debate passa a ser travado ao redor do não nivelamento entre fé e saber preservado por Habermas, bem como da instância apropriada para a linguagem política básica do Estado secular acatada pelos três pensadores.

Contra Rawls, com efeito, Habermas defende a tese de que o chamado consenso sobreposto só é possível com a adoção de um ponto de vista moral independente das (e anterior às) doutrinas abrangentes, que sirva de critério normativo para a identificação não arbitrária da razoabilidade das visões de mundo metafísicas e religiosas ${ }^{31}$. Convergindo no objetivo de tornar manifesta uma base pública de justificação sobre questões de justiça política em sociedades marcadas pelo pluralismo de doutrinas morais, filosóficas e religiosas - cuja cultura política democrática é caracterizada por um desacordo razoável -, Rawls e Habermas divergem precisamente acerca do estatuto epistêmico de uma filosofia política normativa, ainda que não fundacionalista e nem metafísica. Ora, o "método de esquiva" rawlsiano deveria ficar circunscrito, na leitura habermasiana, às disputas éticas sobre o valor presumido de estilos e formas de vida discrepantes, não cabendo "abstinência epistêmica" em face de questões morais e políticas que, admitindo em princípio respostas universalmente válidas, requerem uma justificação racional apropriada ao saber filosófico ${ }^{32}$. "Em última análise, portanto, permanece indeterminado qual das duas autoridades deveria ter a palavra final na justificação do conceito político de justiça - fé ou saber", reafirma Habermas em sua recente resenha crítica do livro póstumo de $\operatorname{Rawls}^{33}$. De sua parte, o filósofo alemão resguarda a diferença metodológica entre o saber filosófico, de caráter argumentativo e absolutamente independente da religião, e as formas de discurso derivadas do núcleo dogmático da fé religiosa, única opção aceitável para um pensamento pós-metafísico que, lidando com indispensáveis potenciais de sentido embutidos na linguagem religiosa, cumpre um trabalho de apropriação racional e transformadora dos conteúdos veiculados pelas comunidades de crentes, mas não pretende reduzi-los às razões seculares, até mesmo porque o sentido performativo da fé religiosa não se esgota em nenhum tipo de racionalidade, além do fato de que a experiência religiosa não pode ser integralmente traduzida para a linguagem profana ${ }^{34}$.

No que respeita a Habermas, portanto, Taylor está correto ao diagnosticar que "ele sempre marcou uma ruptura epistêmica entre razão secular e pensamento religioso", embora "sua posição sobre o discurso religioso tenha evoluído consideravelmente" nos últimos tempos ${ }^{35}$. Essa mudança ethic@-Florianópolis, v. 10, n.3,p.39-53, Dez. 2011. 
do enfoque habermasiano sobre a relação entre religião e política - datada mais ou menos da virada do milênio ${ }^{36}$ - pode ser creditada justamente à reelaboração da ideia de razão pública realizada por Rawls, "o primeiro entre os grandes filósofos políticos", diz Habermas, "a levar a sério o pluralismo religioso e metafísico e a lançar um debate frutífero sobre o estatuto da religião na esfera pública»37. Grosso modo, Habermas situa e examina os embates concernentes à interpretação restritiva do papel político da religião no amplo contexto das descrições genealógicas rivais da modernidade ocidental, das controvérsias envolvendo sua autocompreensão pós-metafísica e não religiosa, rejeitando tanto uma visão "separatista", segundo a qual as doutrinas religiosas não deveriam desempenhar nenhum papel em discussões políticas e tomadas de decisões públicas, quanto uma visão "integracionista", de acordo com a qual não deveria haver qualquer restrição ex-ante com respeito às justificações religiosas, quer na esfera pública política, quer no interior das instituições estatais. Sua intenção é discriminar os argumentos incompatíveis com a natureza secular do Estado moderno das objeções justificáveis contra uma compreensão secularista da democracia e do Estado de direito, de modo a estabelecer uma ética da cidadania apropriada ao horizonte de sociedades pós-seculares, entendidas como aquelas que se tornaram conscientes da persistência da religião, de sua contribuição positiva para a vida política, da necessidade de eliminar sobrecargas mentais e psicológicas insuportáveis para os cidadãos religiosos nas instituições democráticas secularizadas, e ainda do imperativo de acomodação das vozes religiosas na esfera pública, de acordo com "processos de aprendizagem complementares" envolvendo as crenças religiosas e as razões seculares. Habermas procura, assim, confrontar-se com objeções - empíricas e normativas - erguidas contra o proviso rawlsiano ${ }^{38}$.

Ambas as objeções são contornadas pelo filósofo alemão mediante um modelo diferente de implementação da ressalva de tradução defendida por Rawls, a qual, se de modo algum impede a introdução de doutrinas abrangentes na discussão política, impõe a cláusula que consiste em traduzir para a linguagem do político, igualmente acessível a todos os cidadãos, os argumentos não públicos - morais, filosóficos e religiosos - utilizados no processo de justificação normativa. De um lado, a objeção empírica de que "muitos cidadãos não podem ou não estão dispostos a fazer a separação exigida entre contribuições expressas em termos religiosos e aquelas expressas em linguagem secular quando tomam posições políticas". De outro lado, a objeção normativa de que "uma Constituição liberal, que existe também para proteger formas religiosas de vida, não deve infligir

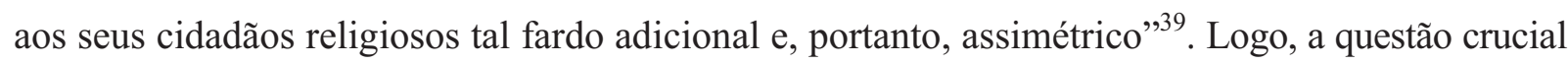
reside na discutível razoabilidade das restrições assimétricas decorrentes de normas governadas 
pelo princípio democrático da igualdade cívica, o que tem a ver com a equidade dos processos de adaptação exigidos pela ordem liberal às doutrinas abrangentes - seculares e religiosas - que não comungam de todos os valores de sua cultura política e nem se encaixam integralmente em sua ordem jurídica. Habermas estabelece uma "cláusula de tradução institucional" - aplicável apenas à esfera pública formal dos parlamentos e dos tribunais, do governo e da administração, nos quais contam somente argumentos seculares - como solução mediadora entre o "separatismo" e o “integracionismo" na questão da religião na esfera pública, algo que se afigura necessário para uma garantia simétrica da liberdade de religião constitutiva do exercício democrático do poder político ${ }^{40}$. Ao recordar que "a assunção de uma razão humana comum constitui a base epistêmica para a justificação de um poder do Estado secular que independe de legitimações religiosas", e, ao mesmo tempo, que "a admissão de exteriorizações religiosas na esfera pública política só passa a ser razoável quando se exige de todos os cidadãos que não excluam a possibilidade de um conteúdo cognitivo dessas contribuições" ${ }^{41}$, ele pretende superar a aparente contradição de uma distribuição desigual de enfoques cognitivos exigentes, responsável pela disseminação de um ressentimento religioso contra o Estado liberal, compreensível apenas com base na (equivocada) interpretação "secularista" ou "laicista" do liberalismo político"42.

A rigor, o ponto de discordância principal entre Taylor e Habermas não se encontra nessa exigência de "tradução institucional" - a despeito, é verdade, de importantes diferenças quanto ao próprio sentido do vocábulo "tradução" -, e sim na clivagem entre razão e religião, bem como na delimitação dos contextos em que a linguagem do Estado deve ser neutra. Assim, para Taylor, a linguagem “oficial” do Estado secular não pode ser religiosa, e isto não por ser religiosa, mas por não ser compartilhada, tanto quanto não o são quaisquer doutrinas filosóficas (abrangentes, no sentido rawlsiano do termo), sendo o uso dessa linguagem restrito à formulação da legislação, dos decretos administrativos e das decisões judiciais, não incluindo a deliberação propriamente dita, quer entre cidadãos, quer entre seus representantes parlamentares ${ }^{43}$. Isso explica o destaque ao reconhecimento habermasiano de que "o poder de aglutinação especial no trato de intuições morais... faz do discurso religioso... um candidato sério a possíveis conteúdos de verdade", não menos que ao seu expurgo das referências religiosas no espaço compreendido "entre uma esfera pública política 'selvagem' e as corporações estatais”, uma vez que no parlamento "a ordem agendada deve permitir ao presidente retirar da ordem do dia posicionamentos ou justificativas religiosas" ${ }^{\text {44 }}$. Taylor acredita que a divergência parece estar mais no raciocínio do que na prática 
recomendada por ambos - a saber, a do respeito por uma "reserva de neutralidade" na linguagem do Estado secular ${ }^{45}$-, mas para Habermas a estratégia deflacionária da diferença entre os tipos de razões oculta uma reação defensiva de quem busca uma fundamentação mais profunda daqueles princípios básicos da ordem moral moderna que constituem o foco do consenso sobreposto a que estamos condenados em regimes constitucionais. Desse modo, a política do secularismo renova a discussão sobre o conceito do político como algo (supostamente) situado para além de sua pura imanência, ou ainda sobre a coerência (ou não) dos ideais políticos fundamentais das sociedades democráticas modernas quando divorciados de suas origens religiosas ${ }^{46}$. 


\section{Notas}

1 "We are condemned to live in an overlapping consensus" (TAYLOR, C. "The Meaning of Secularism". The Hedgehog Review, vol. 12, n. 3 (Fall 2010): 23-34; aqui: p. 33). A sentença reaparece em pelo menos dois outros textos, embora inexplicavelmente sem a preposição ("We are condemned to live an overlapping consensus"): "What Does Secularism Mean?”, in: Dilemmas and Connections: Selected Essays. Cambridge (Mass.): Harvard University Press, 2011, pp. 303-325 (aqui: p. 319); "Why We Need a Radical Redefinition of Secularism”, in: BUTLER, J.; HABERMAS, J.; TAYLOR, C.; WEST, C. The Power of Religion in the Public Sphere. New York: Columbia University Press, edited by Eduardo Mendieta and Jonathan VanAntwerpen, 2011, pp. 34-59 (aqui: p. 48).

${ }^{2}$ Cf. TAYLOR, C. Modern Social Imaginaries. Durham: Duke University Press, 2004. Nessa obra preparatória à sua monumental A Secular Age (Cambridge (Mass.): Harvard University Press, 2007), o autor busca uma definição mais precisa da autocompreensão da modernidade ocidental, para a qual é central a nova concepção da ordem moral baseada no benefício mútuo de seus membros, que passam a compartilhar um "imaginário social" caracterizado por três formas sociais fundamentais: a economia de mercado, a esfera pública e o autogoverno democrático.

${ }^{3}$ Essencial na medida em que a ordem moral moderna se desenvolve dentro de uma estrutura imanente, distinta e separada de uma ordem transcendente da qual se torna lenta e progressivamente independente. O termo "secular", para o autor, não exclui necessariamente a dimensão religiosa, sendo inclusive uma categoria que tem sua origem na cristandade latina. Cf. TAYLOR, C. "The Future of the Religious Past", in: VRIES, H. de (ed.) Religion: Beyond a Concept. New York: Fordham University Press, 2008, pp. 178-244.

${ }^{4}$ TAYLOR, C. "A política liberal e a esfera pública”, in: Argumentos Filosóficos. São Paulo: Loyola, trad. de Adail Sobral, 2000, pp. 275-304; aqui: p. 285 (edição original: Philosophical Arguments. Cambridge (Mass.): Harvard University Press, 1995).

${ }^{5}$ TAYLOR, C. "The Meaning of Secularism”, op. cit., p. 33 (“common philosophy of civility") e p. 25 ("the point of state neutrality is precisely to avoid favoring or disfavoring not just religious positions, but any basic position, religious or nonreligious. We can't favor Christianity over Islam, but also we can't favor religion over against nonbelief in religion, or vice versa"). Cf. tb. Id. "What Does Secularism Mean?”, op. cit., p. 319 e p. 311.

${ }^{6} \mathrm{Na}$ leitura tayloriana, portanto, mas não apenas nela, há uma clara distinção entre o "primeiro" Rawls de $A$ Theory of Justice [1971] (Uma Teoria da Justiça. São Paulo: Martins Fontes, trad. de Jussara Simões, $3^{\mathrm{a}}$ edição, 2008) e o "segundo" Rawls de Political Liberalism [1993] (O Liberalismo Político. São Paulo: Martins Fontes, trad. de Álvaro de Vita, edição ampliada, 2011) quanto ao papel e ao significado da religião na democracia. Contudo, salvo engano meu, Taylor não menciona a introdução de Rawls à edição de 1996 da segunda obra e nem seu último texto de 1997, intitulado "A ideia de razão pública revisitada", o que merecerá nossa atenção mais adiante.

${ }^{7}$ As aspas utilizadas nessa passagem remetem a termos encontrados nos escritos de Charles Taylor já citados, sendo importante esclarecer que o "muro da separação" (wall of separation) e a "laicidade" (laïcité) correspondem a dois modelos da narrativa preponderante da secularização - americano no primeiro caso, francês no segundo - que toma a religião como um caso especial, seja no sentido de distanciamento do Estado em face da religião, seja no sentido de controle do primeiro sobre a segunda. Essas duas formas de autocompreensão do secularismo ocidental interpretam a separação entre Estado e religião como exclusão - mútua ou unilateral, respectivamente -, segundo a interpretação de Rajeev Bhargava, cuja concepção de secularismo baseada na ideia de principled distance é endossada por Taylor. Cf. BHARGAVA, R. "What is Secularism For?", in: Id. (ed.). Secularism and Its Critics. New Delhi: Oxford University Press, new edition, 2005, pp. 486-542. Uma obra representativa do modelo hegemônico da constituição de um regime secular, para Taylor, é a seguinte: LILLA, M. The Stillborn God. New York: Knopf, 2007.

${ }^{8}$ Refiro-me aqui, evidentemente, à obra citada na nota 2, já traduzida em língua portuguesa: TAYLOR, C. Uma Era Secular. São Leopoldo (RS): Editora UNISINOS, trad. de Nélio Schneider e Luzia Araújo, 2010. Uma apresentação bem informada da obra pode ser encontrada em: GORDON, P. E. "The Place of the Sacred in the Absence of God: 
Charles Taylor's A Secular Age". Journal of the History of Ideas, vol. 69, n. 4 (2008): 647-673. Para uma avaliação crítica, cf. LARMORE, C. "How Much Can We Stand?", The New Republic, 9 April 2008, pp. 39-44.

${ }^{9}$ Id., Ibid., p. 16.

${ }^{10}$ Ibid. Taylor fala de "mudança titânica", "mudança de background" e "ruptura com o pano de fundo anterior" na civilização ocidental (Ibid., pp. 26-28) quando se refere à chegada de uma nova era cuja ordem imanente condiciona os tipos de experiência humana, entre elas a crença e a descrença. Embora toda a obra seja dedicada a descrever e a explicar essa transformação, especialmente importante é o Capítulo 15, cujo título (The Immanent Frame) é adotado por um premiado e influente blog da internet (cf. http://blogs.ssrc.org/tif/), fundado no mesmo ano da publicação de A Secular Age e dedicado a estudos interdisciplinares sobre secularismo, religião e esfera pública.

${ }^{11}$ A obra tayloriana polemiza continuamente contra o que ele denomina "histórias de subtração", ou seja, "histórias da modernidade em geral, e da secularidade em particular, que as explicam no sentido de que os seres humanos perderam ou se livraram ou se libertaram de certos horizontes confinadores anteriores ou de ilusões ou de limitações de conhecimento" (Ibid., p. 37). A inovadora narrativa da secularidade em Taylor (secularismo 3) tem sido objeto de muitos debates, cabendo apontar duas obras recentes nas quais ele é autor, respectivamente, de um posfácio e de um capítulo: CALHOUN, C.; VANANTWERPEN, J.; WARNER, M. (eds.). Varieties of Secularism in a Secular Age. Cambridge (Mass.): Harvard University Press, 2010; LEVINE, G. (ed.). The Joy of Secularism: 11 Essays for How We Live Now. Princeton: Princeton University Press, 2011.

${ }^{12}$ As citações de Taylor (“... the understanding of the Enlightenment as an absolute, unmitigated step forward”; “... a move from Revelation to reason alone") são extraídas de um artigo no qual utiliza a expressão empregada por Kant no título da obra "A religião nos limites da simples razão" [1793] (Die Religion innerhalb der Grenzen der blossen Vernunft). Cf. TAYLOR, C. "Die Blosse Vernunft ('Reason Alone')", in: Id. Dilemmas and Connections: Selected Essays, op. cit., pp. 326-346 (aqui: p. 327). Também Habermas, num sentido diferente, se serve da filosofia kantiana da religião para tratar do conteúdo normativo da modernidade no texto "A fronteira entre fé e saber. Sobre o alcance e a importância histórica da filosofia kantiana da religião", in: HABERMAS, J. Entre Naturalismo e Religião: Estudos Filosóficos. Rio de Janeiro: Tempo Brasileiro, trad. de Flávio Siebeneichler, 2007, pp. 235-278 (edição original: Zwischen Naturalismus und Religion. Philosophische Aufsätze. Frankfurt: Suhrkamp, 2005).

13 “.... they seem to reserve a special status for nonreligiously informed reason (let's call this 'reason alone'), as though this latter were able to resolve certain moral-political issues (a) in a way which can legitimately satisfy any honest, unconfused thinker, and (b) where religiously based conclusions will always be dubious, and in the end only convincing to people who have already accepted the dogmas in question" (Id., Ibid., p. 328).

${ }^{14}$ Esses princípios são assim formulados: (a) por Rawls: "nosso exercício do poder político é plenamente apropriado só quando é exercido em conformidade com uma Constituição, cujos elementos essenciais se pode razoavelmente esperar que todos os cidadãos, em sua condição de livres e iguais, endossem à luz de princípios e ideais aceitáveis para sua razão humana comum" (RAWLS, J. O Liberalismo Político, op. cit., p. 161); e (b) por Habermas: "São válidas as normas de ação às quais todos os possíveis atingidos poderiam dar o seu assentimento, na qualidade de participantes de discursos racionais" (HABERMAS, J. Direito e Democracia. Rio de Janeiro: Tempo Brasileiro, trad. de Flávio Siebeneichler, 2 vols., 1997; aqui: vol. I, p. 142) [edição original: Faktizität und Geltung. Beiträge zur Diskurstheorie des Rechts und des democratischen Rechtsstaats. Frankfurt: Suhrkamp, 1992]. Sobre o debate entre esses autores, cf. ARAUJO, L. B. L. Pluralismo e Justiça. Estudos sobre Habermas. São Paulo: Loyola, 2010.

${ }^{15}$ Cf. TAYLOR, C. "What Does Secularism Mean?”, op. cit., pp. 323-324. Cf. tb. Id. "Die Blosse Vernunft ('Reason Alone')", op. cit., pp. 328-329.

${ }^{16}$ TAYLOR, C. "Why We Need a Radical Redefinition of Secularism", op. cit., p. 56 ("What deserve to be called secularist regimes in contemporary democracy have to be conceived not primarily as bulwarks against religion"); RAWLS, J. O Liberalismo Político, op. cit., p. 523; HABERMAS, J. Entre Naturalismo e Religião, op. cit., p. 9.

${ }^{17}$ O que pode ser constatado não só pela leitura de suas respectivas contribuições, mas pelo próprio título do volume citado na primeira nota (The Power of Religion in the Public Sphere), oriundo de um evento de grande repercussão

ethic@-Florianópolis, v. 10, n. 3,p.39-53,Dez. 2011. 
ocorrido em outubro de 2009 em Nova York. O texto de Taylor é o da nota anterior. O de Habermas se intitula "The Political: The Rational Meaning of a Questionable Inheritance of Political Theology", in: BUTLER, J. et al., The Power of Religion in the Public Sphere, op. cit., pp. 15-33. Aos seus ensaios segue-se um debate mediado por Craig Calhoun (cf. "Dialogue: Jürgen Habermas and Charles Taylor", pp. 60-69).

${ }^{18}$ RAWLS, J. "Introdução à edição de 1996”, in: O Liberalismo Político, op. cit., pp. XXXIX-LXX (aqui: p. XLI).

${ }^{19}$ Cf. Id., Ibid. pp. LIV-LXIII. A intenção de Rawls, expressa em carta de julho de 1998 a sua editora na Columbia University Press, era fazer uma revisão geral da obra, o que não foi possível em virtude de sua doença terminal. No entanto, a carta indica claramente que as alterações tinham como ponto de partida seu último artigo ("The Idea of Public Reason Revisited". University of Chicago Law Review, 64 (1997): 765-807), o qual, nas palavras de Rawls, "é de longe a melhor formulação que consegui fazer das ideias de razão pública e liberalismo político. (...) Em particular, enfatizo a relação entre a razão pública e o liberalismo político com as principais religiões que se baseiam na autoridade da Igreja e do texto sagrado e que não são elas próprias, portanto, liberais. A despeito disso, sustento que, exceto no caso do fundamentalismo, essas religiões podem dar apoio a um regime democrático constitucional. Isto é verdade para o catolicismo (desde o Vaticano II) e para grande parte do protestantismo, do judaísmo e do islã" (RAWLS, J. “A ideia de razão pública revisitada”, in: O Liberalismo Político, op. cit., pp. 519-583; aqui: p. 520).

${ }^{20}$ Id. “A ideia de razão pública revisitada", in: O Liberalismo Político, op. cit., p. 549.

21 "What's important is that people give the kinds of reasons that can be understood and appraised apart from their particular comprehensive doctrines. So the idea of public reason isn't about the right answers to all these questions, but about the kinds of reasons that they ought to be answered by" (RAWLS, J. "Commonweal Interview with John Rawls", in: Id. Collected Papers, Cambridge (Mass.): Harvard University Press, edited by Samuel Freeman, 1999, pp. 616-622; aqui, p. 619). A entrevista foi concedida em janeiro de 1998 e publicada originalmente em uma revista católica liberal: Commonweal, vol. 125, n. 16 (September 25, 1998): 12-17.

${ }^{22}$ Id., Ibid., p. 620 ("People can make arguments from the Bible if they want to. But I want them to see that they should also give arguments that all reasonable citizens might agree to. Again, what's the alternative? How are you going to get along in a constitutional regime with all these other comprehensive doctrines?").

${ }^{23}$ Desenvolvo esse ponto no artigo (publicado na revista Dissertatio, verão 2011, p. 91-105) intitulado "John Rawls e a visão inclusiva da razão pública". Há controvérsia entre os estudiosos do pensamento rawlsiano sobre os ganhos e as perdas dessa posição mais permissiva do liberalismo político. Para uma defesa da wide view da razão pública, cf. BOETTCHER, J. "Public reason and religion", in: BROOKS, T.; FREYENHAGEN, F. (eds.). The Legacy of John Rawls. London: Continuum, 2007, pp. 124-151. Para uma apreciação menos condescendente no tocante ao relaxamento de restrições impostas às doutrinas abrangentes no fórum político público, cf. LARMORE, C. "Public Reason”, in: FREEMAN, S. (ed.). The Cambridge Companion to Rawls. Cambridge: Cambridge University Press, 2003, pp. 368-393.

${ }^{24}$ RAWLS, J. “A ideia de razão pública revisitada”, in: O Liberalismo Político, op. cit., pp. 536-537.

${ }^{25}$ Id., Ibid., p. 543.

${ }^{26}$ Independente da importância da religião e das convicções religiosas como temas de sua filosofia política, como se evidencia pela publicação post mortem de seu trabalho de conclusão do Bacharelado em Filosofia na Universidade de Princeton, em dezembro de 1942, e de uma declaração pessoal sobre a questão, redigida provavelmente em 1997: RAWLS, J. A Brief Inquiry into the Meaning of Sin and Faith: With “On My Religion”. Cambridge (Mass.): Harvard University Press, edited by Thomas Nagel, 2010.

${ }^{27}$ Cf. RAWLS, J. “Commonweal Interview with John Rawls”, in: Id. Collected Papers, op. cit., pp. 619-620. Acerca do tema da religião em Rawls, considerando toda a sua produção, cf. DOMBROWSKI, D. Rawls and Religion: The Case for Political Liberalism. Albany: State University of New York Press, 2001.

${ }^{28}$ RAWLS, J. O Liberalismo Político, op. cit., pp. 259-260, nota 7.

ethic@-Florianópolis, v. 10, n. 3, p.39-53, Dez. 2011. 
${ }^{29}$ TAYLOR, C. “The Polysemy of the Secular”. Social Research, vol. 76, n. 4 (2009): 1143-1166; aqui: p. 1163 (“... there are zones of a secular state in which the language used has to be neutral") e p. 1164 ("... the lines are hard to draw, and they must always be drawn anew. But such is the nature of the enterprise that is the modern secular state. And what better alternative is there for diverse democracies?"). Cf. tb. Id. "What Does Secularism Mean?", op. cit., pp. 320-321.

${ }^{30}$ Ambiguidade possível porque Larmore tem razão ao observar que Rawls nem sempre distingue claramente entre a “discussão aberta" (open discussion) e a "tomada de decisão" (decision-making) na discussão política pública, mas é verdade também que, para o segundo, a ideia de razão pública é distinta de seu ideal, que é concretizado por todos os cidadãos quando pensam em si mesmos como se fossem legisladores. Sobre o assunto, cf. RAWLS, J. "A ideia de razão pública revisitada", in: O Liberalismo Político, op. cit., pp. 526-528. A propósito da importante distinção feita pelo primeiro, cf. LARMORE, C. "Public Reason", in: FREEMAN, S. (ed.). The Cambridge Companion to Rawls, op. cit., pp. 382-384.

${ }^{31}$ Cf. HABERMAS, J. "'Reasonable` versus 'True', or the Morality of Worldviews", in: The Inclusion of the Other. Cambridge (Mass.): MIT Press, edited by Ciaran Cronin and Pablo De Greiff, 1999, pp. 75-101 (edição original: Die Einbeziehung des Anderen. Frankfurt: Suhrkamp, 1996).

${ }^{32}$ Rawls denomina "método de esquiva" (method of avoidance) a estratégia geral de justificação de uma concepção política de justiça, cujo objetivo "é prático, e não metafísico ou epistemológico", apresentando-se "como uma base do acordo político bem informado e voluntário entre cidadãos considerados como pessoas livres e iguais" (RAWLS, J. "Justice as Fairness: Political not Metaphysical”, in: Id. Collected Papers, op. cit., pp. 388-414; aqui: p. 394) [“the aim of justice as fairness as a political conception is practical, and not metaphysical or epistemological... it presents itself... as a basis of informed and willing political agreement between citizens viewed as free and equal persons"]. A expressão "abstinência epistêmica" foi cunhada por Joseph Raz para designar a estratégia rawlsiana de evitamento das pretensões de validade das doutrinas abrangentes no trabalho de reconciliação pela razão pública (cf. RAZ, J. "Facing Diversity: The Case of Epistemic Abstinence". Philosophy and Public Affairs, vol. 19, n. 1 (1990): 3-46).

${ }^{33}$ HABERMAS, J. “The 'Good Life' - A 'Detestable Phrase': The Significance of the Young Rawls's Religious Ethics for His Political Theory". European Journal of Philosophy, vol. 18, n. 3 (2010): 443-454; aqui: p. 452 ("Thus it ultimately remains indeterminate which of the two authorities should have the final word in the justification of the political concept of justice - faith or knowledge"). Trata-se de uma resenha da obra citada na nota 26 , de onde se extrai o curioso parêntese ("frase detestável") do jovem Rawls ao referir-se à assim chamada "vida boa".

${ }^{34}$ Sobre esses aspectos, aqui bastante resumidos, cf. HABERMAS, J. "Um diálogo sobre Deus e o mundo", in: Era das Transições. Rio de Janeiro: Tempo Brasileiro, trad. de Flávio Siebeneichler, 2003, pp. 197-220 (edição original: Zeit der Übergänge. Frankfurt: Suhrkamp, 2001). Trata-se de uma entrevista publicada originalmente em Jahrbuch für Politische Teologie (vol. 3 (1999): 190-211) e retomada pelo entrevistador como capítulo final de uma obra que reúne importantes textos habermasianos sobre a religião (cf. Id. Religion and Rationality: Essays on Reason, God, and Modernity. Cambridge (Mass.): MIT Press, edited by Eduardo Mendieta, 2002). Ainda sobre o diálogo entre fé e razão, além de sua introdução à discussão com o então Cardeal Joseph Ratzinger, hoje Papa Bento XVI, ocorrida em janeiro de 2004 a convite da Academia Católica da Baviera (cf. HABERMAS, J. "Bases pré-políticas do Estado de direito democrático", in: Id. Entre Naturalismo e Religião, op. cit., pp. 115-128), ler o ensaio ("An Awareness of What is Missing”, pp. 15-23) e a réplica de Habermas (“A Reply”, pp. 72-83) no volume contendo as contribuições de um colóquio organizado em fevereiro de 2007 pela Faculdade Jesuíta de Filosofia de Munique: An Awareness of What is Missing: Faith and Reason in a Post-secular Age. Cambridge: Polity Press, 2010 (edição original: Ein Bewußtsein von dem, was fehlt. Eine Diskussion mit Jürgen Habermas. Frankfurt: Suhrkamp, 2008).

35 TAYLOR, C. "Why We Need a Radical Redefinition of Secularism", in: BUTLER, J. et al., The Power of Religion in the Public Sphere, op. cit., pp. 49-50 (“... he has always marked an epistemic break between secular reason and religious thought"; “... Recently, his position on religious discourse has considerably evolved”).

${ }^{36}$ Para uma interpretação da guinada pós-secular do pensamento habermasiano, permito-me remeter o leitor ao meu artigo "Do ateísmo ao agnosticismo metodológico: Habermas e a religião". Tempo Brasileiro, 181-182 (2010): 153-

ethic@-Florianópolis, v. 10, n. 3,p.39-53,Dez. 2011. 
168. O termo "pós-secular" surge pela primeira vez na obra de Habermas, ao que tudo indica, no texto "Fé e Saber", in: HABERMAS, J. O Futuro da Natureza Humana. São Paulo: Martins Fontes, trad. de Karina Jannini, 2004, pp. 135-154 (edição original: Die Zukunft der menschlichen Natur. Frankfurt: Suhrkamp, 2001).

${ }^{37}$ HABERMAS, J. “The 'Good Life' - A 'Detestable Phrase'..., op. cit., p. 452 (“... he was the first among the major political philosophers to take religious and metaphysical pluralism seriously and to launch a fruitful debate concerning the status of religion in the public sphere"). Apresentei a noção de pós-secularismo de Habermas como resultado dos debates atuais sobre a relação entre religião e política, a partir da concepção de cidadania democrática de Rawls, em "Razão pública e pós-secularismo: apontamentos para o debate”.Ethic@, vol. 8, n. 3 (2009): 155-173.

${ }^{38}$ Cf. HABERMAS, J. “Religião na esfera pública. Pressuposições cognitivas para o 'uso público da razão' de cidadãos seculares e religiosos", in: Id. Entre Naturalismo e Religião, op. cit., pp. 129-167. Sobre esse confronto, cf. COOKE, M. "A Secular State for a Post-secular Society? Postmetaphysical Political Theory and the Place of Religion". Constellations, vol. 14, n. 2 (2007): 224-238; LAFONT, C. "Religion in the Public Sphere: Remarks on Habermas's Conception of Public Deliberation in Post-secular Societies”. Constellations, vol. 14, n. 2 (2007): 239259; YATES, M. "Rawls and Habermas on Religion in the Public Sphere". Philosophy and Social Criticism, vol. 33, n. 7 (2007): 880-891; FERRARA, A. “The Separation of Religion and Politics in a Post-secular Society". Philosophy and Social Criticism, vol. 35, nos. 1-2 (2009): 77-91.

${ }^{39}$ HABERMAS, J. "The Political: The Rational Meaning of a Questionable Inheritance of Political Theology", in: BUTLER, J. et al., The Power of Religion in the Public Sphere, op. cit., p. 25 (“... many citizens cannot or are not willing to make the required separation between contributions expressed in religious terms and those expressed in secular language when they take political stances”; “... a liberal constitution, which also exists to safeguard religious forms of life, must not inflict such an additional, and hence asymmetrical, burden on its religious citizens").

${ }^{40}$ Tais visões "separatista" e "integracionista” representam certamente posições minoritárias, e, nessa medida, "tipos ideais" no tratamento do tema da religião na esfera pública. Uma recomendável antologia de textos baseada nessa tipologia ideal é a seguinte: CLANTON, J. (ed.) The Ethics of Citizenship: Liberal Democracy and Religious Convictions. Waco (Texas): Baylor University Press, 2009.

${ }^{41}$ HABERMAS, J. "Religião na esfera pública...”, in: Id. Entre Naturalismo e Religião, op. cit., pp. 135 e 157-158.

${ }^{42}$ Em mais de uma ocasião Habermas identifica na crítica de Taylor à justificação de princípios constitucionais com base na "simples razão" - a blosse Vernunft kantiana de que falamos antes - tal ressentimento subliminar em círculos religiosos. Cf. p. ex.: "The Political: The Rational Meaning of a Questionable Inheritance of Political Theology", op. cit., p. 23; "The 'Good Life' - A 'Detestable Phrase'..., op. cit., p. 451. Sobre as motivações profundas que animam a obra filosófica tayloriana, cf. TAYLOR, C. “A Catholic Modernity?”, in: Id. Dilemmas and Connections: Selected Essays, op. cit., pp. 167-187.

${ }^{43}$ Cf. TAYLOR, C. "Why We Need a Radical Redefinition of Secularism", in: BUTLER, J. et al., The Power of Religion in the Public Sphere, op. cit., pp. 50-51.

${ }^{44}$ HABERMAS, J. “Religião na esfera pública...”, in: Id. Entre Naturalismo e Religião, op. cit., pp. 148-149.

${ }^{45}$ Cf. TAYLOR, C. "Why We Need a Radical Redefinition of Secularism”, op. cit., p. 58, nota 12.

${ }^{46}$ Neste sentido, tanto Habermas quanto Taylor aludem à importante distinção entre le politique e la politique feita por Claude Lefort em seu famoso artigo "Permanence du théologico-politique?", originalmente publicado em 1981 (Le Temps de la Réflexion, n. 2, pp. 13-60) e retomado em: LEFORT, C. Essais sur le politique, XIXe-XXe siècles. Paris: Éditions du Seuil, 1986, pp. 251-300. O ensaio foi reproduzido numa coletânea - de resto, excelente - sobre o tema da "teologia política" (cf. VRIES, H. de; SULLIVAN, L. (eds.). Political Theologies: Public Religions in a Post-Secular World. New York: Fordham University Press, 2006), na qual também é transcrito o texto de Habermas citado na nota 34 ("Bases pré-políticas do Estado de direito democrático", in: HABERMAS, J. Entre Naturalismo e Religião, op. cit., pp. 115-128). 